\title{
Post-traumatic and emotional symptoms in different subgroups of patients with mild head injury
}

Citation for published version (APA):

Bohnen, N., Twijnstra, A., \& Jolles, J. (1992). Post-traumatic and emotional symptoms in different subgroups of patients with mild head injury. Brain Injury, 6(6), 481-487. https://doi.org/10.3109/02699059209008145

Document status and date:

Published: 01/01/1992

DOI:

10.3109/02699059209008145

Document Version:

Publisher's PDF, also known as Version of record

\section{Please check the document version of this publication:}

- A submitted manuscript is the version of the article upon submission and before peer-review. There can be important differences between the submitted version and the official published version of record. People interested in the research are advised to contact the author for the final version of the publication, or visit the DOI to the publisher's website.

- The final author version and the galley proof are versions of the publication after peer review.

- The final published version features the final layout of the paper including the volume, issue and page numbers.

Link to publication

\footnotetext{
General rights rights.

- You may freely distribute the URL identifying the publication in the public portal. please follow below link for the End User Agreement:

www.umlib.nl/taverne-license

Take down policy

If you believe that this document breaches copyright please contact us at:

repository@maastrichtuniversity.nl

providing details and we will investigate your claim.
}

Copyright and moral rights for the publications made accessible in the public portal are retained by the authors and/or other copyright owners and it is a condition of accessing publications that users recognise and abide by the legal requirements associated with these

- Users may download and print one copy of any publication from the public portal for the purpose of private study or research.

- You may not further distribute the material or use it for any profit-making activity or commercial gain

If the publication is distributed under the terms of Article $25 \mathrm{fa}$ of the Dutch Copyright Act, indicated by the "Taverne" license above, 


\title{
Post-traumatic and emotional symptoms in different subgroups of patients with mild head injury
}

\author{
N. BOHNEN, A. TWIJNSTRAt and J. JOLLES \\ Department of Neuropsychology and Psychobiology, University of Limburg, \\ Maastricht and $†$ Department of Neurology, University Hospital Maastricht, The \\ Netherlands
}

(Received 1 September 1991; accepted 20 October 1991)

\begin{abstract}
Post-concussional symptoms, such as headache, dizziness and irritability, are thought to result from the emotional stress associated with decreased cognitive performance after a head injury. A questionnaire-based investigation was carried out in 71 patients with mild head injury (MHI), using a heterogeneous item pool in order to study the interrelationships between traditional post-concussive complaints, cognitive problems, and more emotional and functional complaints. Factor analysis indicated that post-concussive symptoms loaded together with items on problems associated with decrcased work performance and fatigability on a first factor, whereas psychovegetative and emotional complaints loaded together on a second factor. Two rating scales were constructed from the relevant items and were used to comparc between subgroups of MHI patients and non-concussed controls. Patients with uncomplicated MHI had significantly higher scores than non-concussed subjects on the post-concussive-cognitive scale, but not on the emotional-vegetative scale. Paticnts with multiple head injuries or pre-cxisting emotional problems had higher scores on both the post-concussive-cognitive scale and the cmotional-vegetative scale than MHI paticnts without a history of emotional problems. Reliable rating scales may be useful in multidiagnostic studies of $\mathrm{MHI}$ patients.
\end{abstract}

\section{Introduction}

In the past two decades there has been a plethora of studies examining the psychological sequelae of closed head injury (see also [1]). The focus of these studies was on patients with severe head injury, where post-traumatic amnesia exceeded 24 hours, and usually 1 week [2-4]. However, most of the neurobehavioural symptoms that are present in more severely head-injured patients-such as disturbed personality adjustment, psychomotor retardation, impulsivity and inaccurate self-appraisal-are generally absent in patients with mild head injury [2].

The so-called 'post-concussional syndrome' consists of subjective and quasi-organic complaints, such as headache, dizziness, fatigue, irritability, poor concentration, and sensitivity to external stimuli [5]. The aspecific and vague nature of post-concussional symptoms (PCS) cause researchers methodological difficulties when they try to quantify or conceptualize these complaints, and this has led to an enstuing controversy about the

Address correspondence to: N. Bohnen, Department of Neuropsychology and Psychobiology, University of Limburg, P.O. Box 616, 6200 MD Maastricht, The Netherlands. 
physiogenetic versus psychogenetic origin of the complaints $[5,6]$. Recently, factor analysis techniques have been used to identify different dimensions within the syndrome in populations of minor to severe head-injured patients. Results indicate that typical organic factors, such as severe memory deficits or frontal neurobehavioural symptoms, correlate with the severity of the trauma, but that patterns of so-called post-concussional symptoms do not $[3,4,7,8]$. The latter complaints have been interpreted as being secondary to the chronic emotional stress that patients experience when they are not able to cope with extra mental effort due to the post-traumatic cognitive deficits [3].

Because there are no studies that have focused solely on the post-concussive complaints of a homogeneous population of patients with mild head injury (MHI), the present study was performed to investigate the interrelationships between traditional post-concussive complaints and more emotional and functional symptoms. Therefore, a questionnaire-based investigation, using a heterogeneous item pool consisting of both traditional PCS symptoms and rather aspecific emotional and functional items, was completed by MHI patients with a PTA of less than 60 minutes. In addition, rating scales derived by factor analysis werc used to assess behavioural differences between subgroups of patients with uncomplicated and complicated $\mathrm{MHI}$ in comparison with non-concussed controls.

\section{Subjects and methods}

Subjects

Patients were selected from a larger population $(n=71)$ of consecurively admitted patients with MHI who were willing to participate in a study and who lived close enough to allow follow-up assessments. The criteria for inclusion in the study included a period of unconsciousness ranging from several seconds to 15 minutes, post-traumatic amnesia for less than 60 minutes, an EMV (Glasgow Coma) score for each patient on admission of 15 , and no evidence of a focal neurological deficit or of a skull fracture. Forty-six patients (23 females and 23 males; mean age $28.3 \pm 14.9 \mathrm{yr}$ ) appeared to have uncomplicated head injury without a prior history of complaints that could affect the study. The patients were examined initially within 6-14 days after injury, with a follow-up assessment 5 weeks after the trauma ( $4-6$ weeks). There were 25 patients ( 7 females, 18 males; mean age $36.7 \pm$ $17.1 \mathrm{yr}$ ) who had complicated MHI because of the presence of one of the following conditions: a history of pre-existing emotional problems, the presence of a concomitant orthopaedic injury, a previous head injury within the past 10 years, or the consumption of alcohol at the time of the trauma. Patients with uncomplicated MHI were matched for age, sex and educational level [9] with non-concussed control subjects who were recruited from a pool of healthy volunteers $(n=43$, mean age $29 \cdot 2 \pm 14 \cdot 2 \mathrm{yr}$ ). All subjects gave their informed consent.

\section{Post-concussive symptoms}

A checklist of post-concussive symptonns was completed, which included items such as headache, dizziness, nausea, difficulties with concentration and memory, fatigue, sleep disturbances and blurred vision. As these symptons also occur in healthy individuals [10], the symproms were scored for the absolutely or relatively increased appearance after the injury in comparison with the pre-traumatic condition. All but three of the 46 patients with uncomplicated $\mathrm{MHI}$ complained of one or more PCS 10 days after the injury. 
Patterns of behavioural dysfunction

A questionniere consisting of 26 items regarding a number of post-concussive and cognitive-energetic complaints, as well as a series of emotional and vegetative complaints, was filled out by the total group of MHI patients $(n=71)$ about 10 days after the trauma in order to construct different rating scales. The first step was to select different subgroups of intercorrelated items by means of factor analysis. The second step was to assess the internal consistency of each subgroup of items in order to construct reliable rating scales. This was done by principal components analysis (with varimax rotation [11]. Two factors were found (Table 1). To minimize misspecification, factor loadings were considered relevant if they achieved a value of \pm 0.45 or more.

Factor 1 (post-concussive-cognitive complaints; eigenvalue=6-44) consisced of 11 high-loading items of rypical post-concussional symptoms, such as headache, dizziness, intolerance to light, noise and other extemal stimuli, together with items indicating problems with decreased work capacity and efficiency, tiredness, difficulty doing things simultaneously, and diminished concextration.

Factor II (emotional-vegetative; eigenvalue $=5.09$ ) included 14 high-loading items of rather aspecific psychovegetative functional symptoms, for examplc, complaints of heart palpitations, wet hands, dyspnoea, flushing, problems with digestion, and having a tense feeling in the chest, as well as items of depression, emotional lability (e.g. crying more easily, being easily defeated, loss of initiative and restlessness), and decreased libido. The 'irritability' item loaded on both factors, whereas the items on problems concerning falling asleep and waking up at night did not specifically load high on any factor.

According to the classical test theory of item analysis, the internal consistency of the two groups of high-loading items on each factor was calculated (Cronbach's alpha). Cronbach's alpha for the first group (11 items) was 0.92 and was 0.86 for the second group of 14 items. These two groups may each be considered to form a scale [12]. Total scores were calculated by summing the original scores for the selected items of each scale. The response to each question was scored according to the severity or intensity of the complaint: $1=$ no, 2 = somewhat, $3=$ moderately or regularly, and $4=$ much or many/frequently.

\section{Results \\ Rating scale scores in patients with uncomplicated MHI and matched non-concussed controls}

Table 2 presents the mean scores on the two scales for the two groups. Patients with uncomplicated $\mathrm{MHI}$ complained of post-concussive and cognitive symptoms significantly more than controls (Wilcoxon $z=3.38 ; p<0.001$ ). In contrast, there was no significant difference between the two groups on the emotional-vegetative scale $(z=0.89 ; n s)$. As can be seen from Figure 1, correlational data indicated that there was a positive relationship between the two scales in both the concussed $(R s=0.73 ; p<0.001)$ and the non-concussed group $(R s=0.69 ; p<0.001)$.

\section{Recovery}

Mean scores on the two scales decreased significantly 5 weeks after an uncomplicated head injury (scale 1 (post-concussive--cognitive scale): -3.02 (sv 5.61); $t=-3.28, p<0.01$; for scale II (emational-vegetative scalc): $-1 \cdot 28$ (SD $3 \cdot 18$ ), $t=2 \cdot 28, p<0 \cdot 05$ ). 
Tible 1. Principal conponemus analysis with varimax rotution of the putient series. Highloading items are shown in italics.

\begin{tabular}{lcc}
\hline & $\begin{array}{c}\text { FI } \\
\text { postconcussive/ } \\
\text { cognitive }\end{array}$ & $\begin{array}{c}\text { FII } \\
\text { emotional/- } \\
\text { vegetative }\end{array}$ \\
\hline Headache & 0.68 & 0.27 \\
Falling asleep & 0.41 & 0.30 \\
Restless & 0.35 & 0.46 \\
Chest & -0.02 & 0.46 \\
Digest & -0.09 & 0.45 \\
Work & 0.76 & 0.11 \\
Light & 0.60 & 0.06 \\
Small cffort & 0.80 & 0.18 \\
Flushing & 0.31 & 0.52 \\
Concentration & 0.64 & 0.07 \\
Dyspnoea & 0.33 & 0.59 \\
Trouble & 0.63 & 0.33 \\
Tired & 0.67 & 0.37 \\
Fainting & 0.25 & 0.58 \\
Heart Palpit & 0.16 & 0.75 \\
Noise & 0.65 & 0.20 \\
Simul & 0.58 & 0.20 \\
Dizzy & 0.70 & 0.10 \\
Depr & 0.40 & 0.62 \\
Wet hands & 0.09 & 0.50 \\
Crying & 0.20 & 0.53 \\
Libido & 0.30 & 0.60 \\
Irritable & 0.57 & 0.50 \\
Initiative & 0.44 & 0.51 \\
Awakc at night & 0.25 & 0.43 \\
Easily defeated & 0.41 & 0.64 \\
\hline & &
\end{tabular}

Chest $=$ tense feeling in chess; Conc $=$ trouble concentrating; Crying $=$ crics morc easily; Depr $=$ depressed; Digest $=$ problems with digestion; Dyspnoae $=$ feels short of breath; Easily defeated = easily overwhelmed by problems; Fainting $=$ feels faint; Flushing $=$ flushes easily; Initiative $=$ loss of initiative; Heart Palpit $=$ heart palpitations; Libido $=$ decreased libido; Light $=$ intolerance to light; Noise = intolerance to noise; Simul $=$ trouble doing things simultaneously; Small efforts = small effort requires much energy; Tired = tires casily; Trouble $=$ has trouble being interrupted by others; Work $=$ decreascd work performance.

In order to study more specifically the traumatic contribution to the correlational pattern between the post-concussive-cognitive and emotional-vegetative scales, the difference scores (5 weeks minus 10 days) for each scale were used for a correlation analysis. A significant relationship between time after injury and the two scales was not found $(R S=0.26 ; \mathrm{ns})$. This indicates that recovery from post-concussive-cognitive complaints does not significantly parallel recovery from emotional-vegetarive complaints.

\section{Rating scale scores in different subgroups of MHI patients with a compromising} condition

Mean data for each scale of each subgroup are presented in Table 2. Subgroups of patients with a particular condition were compared with the group of uncomplicated MHI 


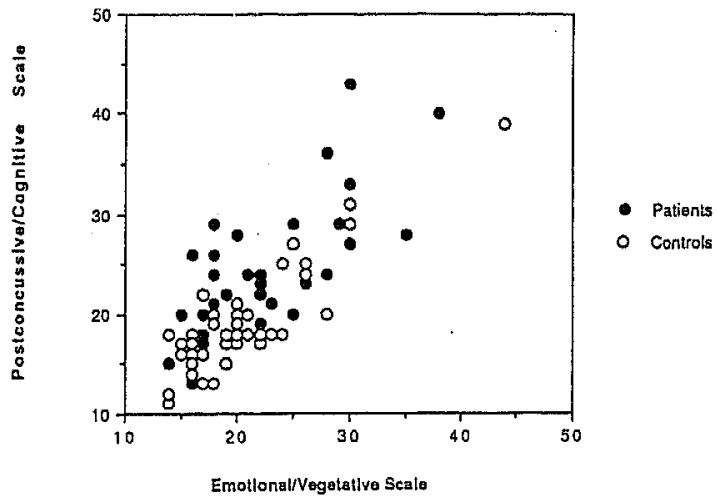

Figure 1. Plot of post-concussive-cognitive complaints ( $Y$-axis) and emotional-vegetative complaints $(X$-axis) for patients with uncomplicated MHI and non-concussed controls.

Table 2. Mean scores on the two scales for different groups (SDs are presented within brackets). Scale I is the post-concussive-cognitive scale, scale Il is the emotional-vegetative scale.

\begin{tabular}{llll}
\hline & $n$ & Scale I & Scale II \\
\hline Uncomplicated MHI patients & 46 & $23 \cdot 6(7 \cdot 1)$ & $21 \cdot 6(6 \cdot 2)$ \\
Non-concussed controls & 43 & $18 \cdot 9(4 \cdot 8)$ & $20 \cdot 5(5 \cdot 3)$ \\
Patients with a previous head injury & 9 & $32 \cdot 2(5 \cdot 2)$ & $32 \cdot 4(4 \cdot 8)$ \\
Patients with pre-cxisting emotional problems & 5 & $32 \cdot 2(5 \cdot 2)$ & $32 \cdot 4(4 \cdot 8)$ \\
Patients with an orthopatdic injury & 5 & $23 \cdot 2(9 \cdot 1)$ & $26 \cdot 0(7 \cdot 7)$ \\
\hline
\end{tabular}

patients. Analysis of coveriance was used in order to adjust for age and sex.

Patients who had a previous head trauma within the past 10 years $(n=9)$ had higher scores on both the post-concussive-cognitive scale $(F(1,51)=3.99 ; p<0.05)$ and the emotional-vegetative scale $(F(1,51)=5.63 ; p<0.05)$ than the control patients. Patients with pre-existing emotional problems $(n=5)$ also scored higher on the post-concussivecognitive scale $(F(1,47)=4.48 ; p<0.05)$ but had disproportionately higher scores on the emotional-vegetative scale $(F(1,47)=11.84 ; p<0.01)$. Patients who had sustained MHI together with an orthopaedic injury $(n=5)$ did not differ significantly on either scale (scale I: $F(1,47)<1 ;$ ns); (scale II: $F(1,47)=1.49 ;$ ns), but tended to have higher scores on the emotional-vegetative scale (Table 2).

\section{Discussion}

Principal components analysis with varimax rotation yielded two clearly distinct factors in a general population of $\mathrm{MHI}$ patients. The first factor indicated that post-concussive symptoms of headache, dizziness and intolerance to environmental stimuli loaded together with items of decreased cognitive and work performance. In contrast, items of emotional lability and depression loaded together with rather aspecific vegetative symptoms. These results provide evidence that, even in a population of MHI patients, post-concussive sequelae can be distinguished from more emotional and functional complaints. The scores on the two scales correlated with each other in both the patient and the control group. 
However, further analysis of the differences between the two groups indicated that MHI patients without a previous history complained significantly more about post-concussive and cognitive problems, but did not complain disproportionately more about emotional and functional symptoms than the non-concussed controls. The decrease in post-concussive and cognitive complaints did not parallel the decrease in emotional and vegetative complaints. Therefore, it appears that the emotional and vegetative complaints may reflect an aspecific correlate of the post-concussive sequelae.

According to the coping hypothesis $[3,8]$, post-concussive complaints may result from the chronic effort of patients to compensate for their cognitive deficits that may lead to a chronic stress reaction. This notion is supported by data reported by Bornstein [13] who found a positive relationship between emotional disturbance and cognitive deficits in patients with ninor head injury. Although Hinkeldey and Corrigan [8] suggested that traditional post-concussive complaints may represent an (hypothesized) increase in emotional distress expressed through bodily symptoms, the present data indicate that this may be true for the vegetative symptoms. The complaints of headache, dizziness and intolerance to external stimuli did not load together with the vegetative and emotional complaints and may therefore represent a distinct subgroup of post-traumatic complaints. In addition, Barth et al. [14] found that selected symptoms of headache, nausea, dizziness and memory problems were rather unique to head-injured patients in comparison with non-concussed patients with an orthopaedic injury or healthy subjects. It might be possible that emotional and vegetative complaints are more related to a paticnt's reduced ability to cope with environmental stress than to post-traumatic brain dysfunction per se.

Analysis of the data of different subgroups of MHI patients with a compromising condition supports previous reports that multiple concussions may have a cumulative and aggravating effect [15], and that patients with pre-existing emotional problems report disproportionately more emotional and functional symptoms than control patients with uncomplicated MHI. Recent studies $[7,10]$ reported that patients with system and orthopaedic injuries had more limitations in psychosocial functioning than patients with head injury alone. Although we did not find a significant difference on the two scales between MHI patients with a concomitant orthopaedic injury and controls, the former group of patients tended to have higher scores on the emotional-vegetative scale. Moreover, the small number of subjects in the present study and the fact that hospitalized patients with more serious orthopaedic problems were excluded do not allow us to draw firm conclusions.

It needs to be stressed that this study of post-commotional complaints was confuned to MHI patients in an early phase after the trauma and that with more prolonged post-injury times, and especially with persistent symptoms, developing symptoms of anxiety or depression may alter the constellation of the syndrome [5]. In summary, the present findings indicate that patients with uncomplicated $\mathrm{MHI}$ complain more of post-concussive and cognitive complaints, but not disproportionately more of emotional and vegetative complaints, than non-concussed controls. Associated emotional and vegetative complaints form a distinct subgroup of symptoms and appear to be of a secondary nature. Subgroups of patients with a compromising condition tend to report both more post-concussive and emotional complaints than uncomplicated control patients and may therefore bias studies of MHI. Further research is needed to apply the two scales to subgroups of patients with objectively demonstrated deficits in neurobehavioural and cognitive tests in order to explore further the somatic, cognitive, and emotional post-traumatic symptoms in patients with $\mathrm{MHI}$. 


\section{References}

1. Ponsforu, J. L.: Psychological sequelae of closed head injury: time to redress the imbalance. Brain Injury, 4: 111-114, 1990.

2. Levin, H. S. and Grossman, R. G.: Behavioral sequelae of closed head injury. A quantitative study. Archives of Neurology, 35: 720-727, 1978.

3. VAN ZOMEREN, A. H. and VAN DEN BURG, W.: Residual complaints of patients two years after severe head injury. Joumal of Netrology, Neurosurgery, and Psychiatry, 48: 21-28, 1985.

4. Levin, H. S., HIGH, W. M., GoETHE, K. E. et al:: The neurobehavioral rating scale: assessment of the behavioural sequelac of head injury by the elinician. Journal of Neirology, Neurosurvery, and Psychiatry, 50: 183-193, 1987

5. LISHMAN, W. A.: Physiogenesis and psychogenesis in the 'post-concussional syndrome'. British Journal of Psychiatry, 153: 460-469, 1988.

6. BINDER, L. M.: Persisting symptoms after mild head injury: a review of the post-concussive syndrome. Journal of Clinical and Experimental Neuropsychology, 8: 323-346, 1986.

7. Levin, H. S., Garry, Jr., H. E., HIGH, W. M. et al.: Minor head injury and the postconcussional syndrome: methodological issues in outcome studies. In: H.S. Levin, J. Grafrnan, and H.M. Eisenberg (editors). Neurobehavional Recovery from Head lnjury. (Oxford University Press, New York), pp. 262-275, 1987.

8. HINKELDEY, N. S. and CORRIGAN, J. D.: The structure of head-injured patients' ncurobchavioural complaints: a preliminary study. Brain Injury. 4: 115-133, 1990.

9. Verrage, R.: Intelligentie en lectrijd. Thesis. Assen, The Netherlands, 1964.

10. Dikmen, S., McLean, A. and Temkin, N.: Neuropsychological and psychosocial consequences of minor head injury. Joumal of Neurology, Neurosurgery, and Psychiatry, 49: 1227-1232, 1986.

11. SAS User's Guide: Statistics Version 5 Volume. (SAS Insticure, Inc., Cary, N.C.), 1985.

12. Novick, M. R.: The axioms and principal results of classical test theory. Journal of Mathematical Psychology, 3: 1-18, 1966.

13. Bornstein, R. A., Mill.er, H. B. and van SCHOOR, J. T.: Neuropsychological deficit and emotional disturbance in head-injured patients. Joumal of Neurosurgery, 70: 509-513, 1989.

14. BARTH, J. T., ALVES, W. M., RYAN, Th. V. et al.: Mild head injury in sport: neuropsychological sequelae and recovery of function. In: H.S. Levin, H.M. Eisenberg and A.L. Benton (editors), Mild Head Injury. (Oxford University Press, New York), pp.257-275, 1989.

15. GRONWALL, D. and WRIGitson, P.: Memory and information processing capacity after minor head injury. Joumal of Neurology, Neurosurgery, and Psychiatry, 44: 889-895, 1981. 